\title{
UTILIZAÇÃO DE ECO-INOVAÇÃO NO PROCESSO DE MANUFATURA DE CERÂMICA VERMELHA
}

\author{
Adriana Salete Farias \\ Doutoranda em Recursos Naturais da Universidade Federal de Campina Grande - UFCG \\ Professora da Universidade Federal de Campina Grande - UFCG \\ diana_recife@yahoo.com.br
}

\section{Dayanna Santos Costa}

Graduação em Administração pela Universidade Federal de Campina Grande - UFCG

dayanna-costa@hotmail.com

\section{Lúcia Santana Freitas}

Doutoranda em Administração da Universidad de Valladolid, Espanha

Professora da Universidade Federal de Campina Grande - UFCG

luciasf@ch.ufcg.edu.br

\section{Gesinaldo Ataide Cândido}

Doutor em Engenharia de Produção pela Universidade Federal de Santa Catarina - UFSC Professor da Universidade Federal de Campina Grande - UFCG

gacandido@uol.com.br

\section{RESUMO}

O presente estudo teve como objetivo apresentar e caracterizar uma ecoinovação adotada por uma empresa do setor de cerâmica vermelha. Buscou-se através de um estudo de caso tipificar a ecoinovação adotada no processo produtivo da empresa-alvo. Como principais contribuições teóricas para análise dos dados foram utilizados os modelos de Hohmeyer e Koeschel (citado em Rennings, 2000) e de Rennings (2000). Verificou-se que a aquisição de um novo forno para realizar a etapa de queima se configura como uma ecoinovação de processo que teve como principal fator determinante da adoção dessa ecoinovação o desenvolvimento tecnológico do mercado fornecedor.

Palavras-chave: Ecoinovação; Determinantes de Adoção de Ecoinovação; Manufatura de Cerâmica Vermelha; Gestão Ambiental. 


\section{INTRODUÇÃO}

Inovações voltadas para a sustentabilidade e o estabelecimento de políticas socioambientais nas empresas podem ocorrer por meio de diferentes maneiras de combinar materiais e força de trabalho, quer seja pelo emprego de diferentes meios produtivos, quer, ainda, pelas combinações de novos fatores de produção. Isso pode ser traduzido em novos produtos ou na inserção de um novo atributo à qualidade de um produto já existente, em um novo método produtivo, na abertura de um novo mercado, na descoberta de novas fontes de matérias-primas e em mudanças na composição de um produto, entre outras possibilidades. Assim mudanças dessa natureza podem responder a problemas ambientais existentes, minimizando o impacto ambiental decorrente de uma atividade produtiva necessária e/ou induzindo a novos padrões de consumo.

A inovação voltada para a sustentabilidade, ou ecoinovação, pode ser considerada como a introdução de produtos, processos produtivos, métodos de gestão ou negócios, novos ou significativamente melhorados, para a organização e que traz benefícios econômicos, sociais e ambientais, comparados com alternativas pertinentes. Não se trata apenas de reduzir impactos negativos, mas de adicionar benefícios líquidos. Uma organização inovadora sustentável reúne características essenciais de inovação orientada para a sustentabilidade (Barbieri, Vasconcelos, Andreassi, \& Vasconcelos, 2010).

Ao se comprometer com o desenvolvimento sustentável, uma empresa deve necessariamente mudar sua forma de atuação para, no mínimo, reduzir os impactos sociais e ambientais adversos. É importante que haja oferta de produtos gerados na perspectiva da preservação ambiental incorporando características que facilitem seu reaproveitamento, reciclagem ou remanufatura, ou ainda um descarte seguro e com menor prejuízo ambiental. Também é importante o esforço conjunto das instituições governamentais, industriais ou grupos sociais no sentido de induzir a um consumo sustentável. Isso muda o foco da inovação tecnológica que apenas visa à elevação da eficiência econômica dos sistemas produtivos para a inovação tecnológica objetivando a proteção ambiental, tanto de caráter preventivo quanto corretivo.

A mudança na forma de produzir nas empresas pode ser impulsionada pela melhor compreensão da magnitude e dos riscos dos impactos ambientais globais. Nesse sentido, as contribuições de instituições sociais são importantes para o aprofundamento do processo de conscientização ecológica e de mudanças de valores culturais. Além disso, a regulamentação ambiental é necessária para promover os incentivos ao investimento, à inovação tecnológica e ao aperfeiçoamento da gestão ambiental.

Revista de Administração e Inovação, São Paulo, v. 9, n.3, p. 154-174, jul/set. 2012. 
Teles e Arraes (2004) afirmam que, sem a regulamentação ambiental, a utilização de recursos naturais pode ser levada à exaustão. Por sua vez, a maneira como a regulação influenciará a diminuição da degradação dependerá do ambiente institucional presente. Por ambiente institucional, esses autores referem-se a todos os fatores, como regras de conduta, leis, convenções, mecanismos políticos e organizações como polícias, tribunais, associações, órgãos ambientais, que implementam e garantem os direitos de propriedade.

As empresas são, em princípio, responsáveis pelas consequências de suas operações, incluindo os impactos diretos, assim como as externalidades que afetam terceiros, o que envolve toda a cadeia produtiva e o ciclo de vida dos seus produtos e serviços. A recente associação de responsabilidade social empresarial ou corporativa aos preceitos do desenvolvimento sustentável ampliou o conceito para responsabilidade socioambiental, considerando a atuação das empresas e o impacto de suas atividades produtivas, que afetam a qualidade de vida e comprometem o futuro do planeta pelo uso de recursos naturais escassos (Vinha, 2003).

No âmbito da gestão empresarial, gradativamente, as empresas têm incorporado às ações de responsabilidade social políticas e práticas de conteúdo ambiental, por diversas razões, e percebem que preservar a qualidade socioambiental pode ser uma oportunidade de investimento e de ganhos futuros, além de poder se transformar numa vantagem competitiva. Como consequência, a compreensão da responsabilidade socioambiental como posicionamento competitivo pode levar as organizações a melhorar seu desempenho nas dimensões social, ambiental e econômica à medida que a preservação ambiental torna-se um fator de diferenciação para as empresas, permitindo incluir preocupações ambientais nas estratégias empresariais.

Barbieri et al. (2010) reconhecem que o aprimoramento dos modelos gerenciais com a visão de adaptar as organizações ao desenvolvimento sustentável é necessário. Por isso, a investigação relativa às formas da institucionalização da gestão ambiental em âmbito global, ao desenvolvimento de tecnologias sustentáveis e à gestão de inovações para o desenvolvimento sustentável será tema cada vez mais importante nos estudos futuros, podendo ser aplicada aos mais variados tipos de atividades econômicas.

Tomando como referência o setor de cerâmica vermelha, responsável pela produção de tijolos, telhas e blocos a partir da extração, do beneficiamento e da queima de argila, observa-se a necessidade de diminuir perdas no processo de produção, melhorar as condições de trabalho e reduzir o impacto ambiental decorrente dessa atividade produtiva, considerando que em cada fase do processo produtivo insumos como matéria-prima e energia são empregados, recursos humanos são necessários e resíduos são gerados e lançados ao ambiente (Grigoletti \& Sattler, 2003). 
Os principais impactos ambientais relacionados à indústria de cerâmica vermelha incluem a degradação das áreas de extração da argila, além de alto consumo de água e energia; a geração de resíduos sólidos decorrentes de perdas por falhas na qualidade do produto semiacabado ou acabado e sua disposição no solo; a emissão de poluentes aéreos e a liberação de gases $\left(\mathrm{CO}_{2}\right)$, principalmente na etapa da queima dos produtos.

Nesse contexto, a adoção de novas tecnologias de produção que possam elevar a eficiência produtiva, melhorar as condições de trabalho e ao mesmo tempo reduzir o impacto ambiental se torna cada vez mais necessária à gestão das empresas da indústria de cerâmica vermelha.

No Brasil o setor de cerâmica vermelha é composto, em grande parte, por empresas familiares de micro, pequeno e médio porte e com processos produtivos e tecnologia, em muitos casos, defasados. Segundo dados de uma pesquisa realizada em 2003 pela Associação Brasileira de Cerâmica (ABC, 2003), as empresas do setor de cerâmica vermelha estão localizadas nas diversas regiões do País, instalando-se em localidades que apresentam disponibilidade de matéria-prima.

Na Paraíba, uma empresa do setor de cerâmica vermelha, aqui denominada de Cerâmica Alfa, tem adotado uma ecoinovação em uma de suas principais etapas da fabricação: a queima. Este estudo teve como objetivo analisar as condições relativas à adoção dessa nova tecnologia na empresa estudada. Tal análise foi suportada por duas contribuições teóricas relacionadas ao desenvolvimento/adoção de inovações voltadas para a sustentabilidade ou ecoinovações. A primeira contribuição diz respeito à utilização do modelo de Hohmeyer e Koeschel (citado em Rennings, 2000) para caracterizar a inovação em relação ao estágio de sua incorporação/ adição ao sistema produtivo bem como identificar a natureza de sua utilização no sistema produtivo. Outro modelo utilizado nessa análise foi o de Rennings (2000) que identifica os fatores determinantes da adoção de ecoinovação em uma empresa.

Por suas características, este estudo é de natureza predominantemente exploratória, tendo como finalidade maior auxiliar na compreensão dos ganhos econômicos, sociais e ambientais que a incorporação da ecoinovação identificada pode agregar à sustentabilidade do setor de cerâmica vermelha.

\section{FUNDAMENTAÇÃO TEÓRICA}

Textos científicos de várias áreas têm lançado luzes ao debate em torno da sustentabilidade, e iniciativas de grupos sociais de direitos humanos e ambientais têm pressionado os governos para que assegurem as condições de sobrevivência do planeta para as gerações presente e futura.

Revista de Administração e Inovação, São Paulo, v. 9, n.3, p. 154-174, jul/set. 2012. 
Cohen (2003) afirma que o estilo de vida contemporâneo mostra-se cada vez mais expansivo, móvel e prejudicial ambientalmente. Esse padrão de consumo agrava problemas de exclusão social, custos ecológicos e psicológicos da urbanização acelerada. Por isso, é importante que haja oferta de produtos gerados na perspectiva da preservação ambiental incorporando características que facilitem seu reaproveitamento, reciclagem ou remanufatura, ou ainda um descarte seguro e com menor prejuízo ambiental. Também é importante o esforço conjunto das instituições governamentais, industriais ou grupos sociais no sentido de induzir a um consumo sustentável.

Mudanças dessa natureza dependem, em grande medida, de inovações. Barbieri e Simantob (2007) afirmam que as inovações constituem peça-chave para que as organizações possam contribuir para o desenvolvimento sustentável, visando estabelecer um novo modo de produção da subsistência humana que seja compatível com a capacidade de suporte do planeta e que seja equitativo, pois as disparidades de renda entre regiões, povos e classes constituem o outro lado de uma apropriação desigual dos recursos da Terra.

Sobre a importância das inovações, Schumpeter (1985) afirma que há várias formas de realização, de modo que as inovações podem acontecer por meio da introdução de um novo bem ou de uma nova qualidade de um bem, de um novo método produtivo, da abertura de um novo mercado, de nova fonte de matérias-primas ou de bens semimanufaturados. Em se tratando de inovações para a sustentabilidade, cabe tanto à empresa inovadora quanto ao meio institucional introduzir e sustentar a mudança na oferta de bens e produtos, influenciar o hábito de consumo sustentável e levar o consumidor a compartilhar a necessidade da preservação ambiental.

Rennings (2000) afirma que a inovação para a sustentabilidade, ou ecoinovação, pode ser desenvolvida por empresas ou por organizações sem fins lucrativos e que sua natureza pode ser tecnológica, social ou institucional. Para ele, a ecoinovação tem o atributo de reduzir encargos ambientais relativos a, pelo menos, um tipo de recurso natural. Isso muda o foco da inovação tecnológica apenas visando à elevação da eficiência econômica dos sistemas produtivos e conduz para a inovação tecnológica objetivando a proteção ambiental, tanto de caráter preventivo quanto corretivo.

A incorporação de inovações sustentáveis nas empresas começa muitas vezes com o propósito de atender à demanda ambiental decorrente de regulamentação. Em relação à sustentabilidade de uma atividade produtiva, observa-se que inicialmente a intenção era tratar os resíduos industriais para facilitar sua absorção pela natureza. Esse esforço ficou conhecido como desenvolvimento de soluções end-of-pipe (fim de tubo) porque eram aplicadas apenas no fim do processo produtivo, tendo caráter corretivo. 
É importante destacar a noção de impacto ambiental proposto por Wathern (citado em Sanchez, 2008) que destaca o efeito da ação humana sobre o ecossistema. Para esse autor, o impacto ambiental se constitui na mudança de um parâmetro ambiental, num determinado período e numa determinada área, resultante de uma atividade, comparada com a situação que ocorreria se essa atividade não tivesse sido iniciada. Quando o impacto ambiental se mostra negativo, ele gera degradação ambiental que é percebida pela redução das condições naturais e pela alteração do estado original do ambiente.

A ampliação da visão de gestão ambiental no âmbito da empresa foi direcionada para a produção com mínimo impacto, dentro de limites tecnológicos e econômicos, não se contrapondo ao crescimento. Assim, o conceito de produção mais limpa $(\mathrm{P}+\mathrm{L})$ foi consolidado, expressando aspectos preventivos da gestão ambiental nas empresas, incorporando essa temática desde a concepção, o planejamento, a organização, até a operação produtiva da empresa, e não aguardando que os resíduos sejam gerados para depois procurar tratá-los e descartá-los (Gasi \& Ferreira, 2006).

As ações de $\mathrm{P}+\mathrm{L}$ têm objetivos de redução de impactos ambientais adversos ao longo do ciclo de vida dos produtos, incluindo o pós-consumo. Esse conceito aplica-se não somente às organizações industriais, estendendo-se também à produção de bens e serviços. Sugere ainda a melhoria contínua dos processos produtivos, de forma a torná-los cada vez mais eficientes e menos agressivos ao meio ambiente e à saúde humana.

As metodologias e técnicas realizadas pelas empresas no sentido de atenderem metas de gestão ambiental, inicialmente adotadas no âmbito dos processos internos, favoreceram a estruturação de canais de distribuição reversos na economia.

Acerca dessa abordagem, Leite (2009) define um canal de distribuição reverso como aquele através do qual uma parcela de produtos, com pouco uso, com ciclo de vida útil ampliado ou após a extinção de sua vida útil, retorna ao ciclo produtivo ou de negócio, readquirindo valor em mercados secundários pelo reuso ou pela reciclagem de seus materiais constituintes.

Muitas dessas formas de inovações tecnológicas utilizadas como ferramentas de gestão ambiental nas empresas podem ser observadas no Modelo Hohmeyer e Koeschel (citado em Rennings, 2000) que analisa as tecnologias ambientais de acordo com a etapa em que elas são incorporadas à atividade produtiva de uma empresa. Esses autores propõem que as tecnologias ambientais podem ser integradas ao processo em diferentes momentos: na entrada - por exemplo, através da substituição de insumos nocivos ao meio ambiente ou através da substituição de recursos naturais primários por material reciclado; no processo de produção - através da otimização de um único componente do processo, ou da integração de um novo componente ao processo, ou da integração de componentes alternativos ao processo, ou ainda através da utilização de um processo de produção alternativo; na saída - através da otimização de um componente do produto, ou através da integração de um novo 
componente ao produto, ou através da troca de um componente do produto, ou através da substituição completa do produto.

Além da possibilidade de as inovações voltadas para a sustentabilidade serem incorporadas etamente ao processo produtivo em suas diferentes etapas, Hohmeyer e Koeschel (citado em Rennings, 2000) consideram que esse tipo de inovação pode ocorrer de forma adicionada, ou seja, pode ser incorporada após a finalização do processo produtivo como meio de proteção ambiental. Nesse caso, a inovação visa reduzir os efeitos negativos da produção e do consumo, através do desenvolvimento de tecnologias que viabilizem a remanufatura ou reciclagem dos produtos ou de seus componentes, ou o tratamento dos resíduos industriais, ou dos produtos descartados após o consumo.

É importante considerar que inovações de qualquer tipo exigem investimento em pesquisa e o desenvolvimento de habilidades técnicas e gerenciais por parte do agente inovador, além de demandarem período de tempo significativo até estarem em condições de serem adotadas como novo paradigma de produção. O esforço de uma empresa em inovar gera custos que ela espera recuperar através dos benefícios resultantes de sua adoção.

Sobre o retorno do investimento em inovações, há significativa incerteza e dificuldade de determinação porque uma inovação pode rapidamente ser copiada e assim os benefícios serem apropriados por concorrentes que não tiveram nenhum custo direto com a inovação. No que se refere a inovações de conteúdo ambiental, esse risco é ainda mais presente uma vez que nem sempre o consumidor percebe ou está disposto a pagar mais por um produto que tenha um preço mais elevado porque foi elaborado considerando melhores práticas ambientais no processo produtivo em sua composição.

Para minimizar essas dificuldades, Rennings (2000, p. 326) afirma que políticas públicas de apoio à inovação para a sustentabilidade podem ajudar a diminuir os custos tecnológicos, institucionais e sociais, especialmente nas fases de invenção e de produção no mercado. Por outro lado, a regulamentação ambiental das atividades produtivas pode ser um determinante no comportamento ecoinovador das empresas, famílias e outras instituições, isso porque as regulamentações frequentemente surgem em função de desastres ambientais decorrentes da degradação gerada pela atividade humana e atuam para evitar repetições desses desastres (Romeiro, 1999).

Todavia, se a preservação ambiental depender somente da regulamentação, é necessário ocorrerem perdas mais ou menos severas para que a sociedade e os governos se tornem responsáveis ambientalmente. Outro aspecto é que, dependendo do impacto ambiental adverso gerado, as condições de preservação podem ser ínfimas ou conseguidas apenas em um período de tempo relativamente 
grande. A postura ambiental sob essa perspectiva é predominantemente corretiva, podendo ser menos eficiente em termos de preservação dos recursos naturais.

Pode-se considerar então que a regulamentação é necessária, mas não suficiente para garantir o desenvolvimento sustentável. Outros mecanismos complementares são necessários, na forma de iniciativas originadas nos próprios atores envolvidos em uma atividade produtiva ou com os impactos dela decorrentes, visando atender a demandas ambientais.

Nesse sentido, as empresas maiores tendem a desenvolver suas funções de P\&D e concentram esforços para desenvolver inovações (incrementais ou radicais) no sentido de elevar a eficiência produtiva em termos de custo-benefício. Em função da predisposição à inovação nas grandes firmas, a incorporação de conteúdo ambiental no processo de inovação se torna relativamente mais fácil, tendo em vista a existência de uma estrutura técnica e gerencial apta a incorporar mudanças nos processos produtivos empurradas pelo próprio desenvolvimento tecnológico da atividade.

De outra parte, Hall (2000) chama atenção para o fato de que as empresas mudam suas estratégias em resposta a pressões de várias fontes, destacando que posturas organizacionais podem ser modificadas como resposta a pressões sociais, econômicas ou regulatórias que obrigam empresas a se preocuparem e tratarem as questões ambientais, principalmente se a atividade produtiva é caracterizada como poluidora do meio ambiente. Corroborando com esse pensamento, Rennings (2000, p. 322) apresenta um modelo de fatores determinantes para o desenvolvimento ou adoção de uma ecoinovação nas empresas. De acordo com esse modelo, inovações voltadas para a sustentabilidade ou ecoinovações podem ser: empurradas pelo desenvolvimento tecnológico da atividade, empurradas pela regulamentação da atividade ou puxadas pelo mercado consumidor.

A ecoinovação empurrada pelo desenvolvimento tecnológico se preocupa com a maior eficiência no uso de energia, no uso dos materiais, na qualidade do produto, ou seja, visa otimizar os recursos produtivos através da elevação de sua produtividade. Esse tipo de ecoinovação pode ser desenvolvido pelos fornecedores de tecnologia da atividade produtiva ou pelas próprias empresas produtoras, sendo incorporado aos processos de produção à medida que essas empresas renovam ou ampliam sua capacidade produtiva.

A ecoinovação empurrada pela regulamentação da atividade visa atender a legislação ambiental estabelecida, incorporar padrões de segurança e saúde ocupacional para os trabalhadores das empresas ou ainda preparar a empresa para mudanças esperadas na regulamentação da atividade produtiva.

A ecoinovação puxada pelo mercado consumidor visa atender demandas de consumidores que valorizam aspectos ecológicos incorporados aos produtos. Essas inovações voltadas para a preservação ambiental, quando orientam as estratégias competitivas das empresas, podem assegurar a 
entrada em novos mercados ou ampliar a parcela de mercados já atendidos, podem também contribuir para a redução de custos e melhorar a imagem das empresas, além de auxiliar no desenvolvimento de práticas socioambientais.

Esses fatores podem individualmente determinar o desenvolvimento de ecoinovações nas empresas, como também podem conjuntamente justificar a incorporação de inovações sustentáveis nas empresas, ainda que seja possível identificar a predominância de algum deles.

A inovação para a sustentabilidade, ou ecoinovação, tem características específicas que, segundo Berkhout e Green (2002), devem ser observadas na gestão dos relacionamentos entre as empresas envolvidas na atividade produtiva até a disponibilização para o consumo. Por isso é necessário considerar a importância das contribuições de outros agentes além da empresa, definindo, informando e valorizando a inovação para o ambiente. A necessidade de integração contínua com um amplo conjunto de stakholders tem conduzido para uma acumulação de novas rotinas organizacionais nas empresas, muitas com implicações diretas para os processos de inovação, visando ao gerenciamento sustentável de uma atividade produtiva.

\section{METODOLOGIA}

A presente pesquisa é predominantemente exploratória, pois busca tipificar a ecoinovação utilizada pela empresa Cerâmica Alfa (nome fictício) e os fatores que determinaram a incorporação dessa nova tecnologia ao seu sistema produtivo. Esse tipo de pesquisa, segundo Hair, Babin, Money e Samouel (2005), pode ser muito útil quando se busca investigar práticas inovadoras de produção e gestão, e quando se aplica a temas de estudos relativamente novos, como é o caso dos estudos em torno de ecoinovações.

Em relação aos procedimentos técnicos, foi utilizado o modelo de estudo de caso que consiste no estudo profundo e exaustivo de um ou de poucos objetos de modo que permita o amplo e detalhado conhecimento destes (Gil, 1996). A escolha da empresa se deu principalmente em função de tipicidade, tendo em vista que houve a adoção de uma nova tecnologia no processo produtivo que visa melhorar o desempenho da empresa em vários aspectos, inclusive na redução do impacto ambiental, o que tipifica a adoção de uma ecoinovação.

A primeira etapa da pesquisa consistiu na revisão da literatura em torno da temática de ecoinovação que possibilitou a identificação dos dois modelos teóricos - de Hohmeyer e Koeschel (citado em Rennings, 2000) e de Rennings (2000) - utilizados para orientar a coleta e a análise dos 
dados primários da pesquisa. Esses modelos fundamentaram a estruturação de um roteiro de entrevista que foi aplicado junto aos sujeitos da pesquisa na empresa; notadamente foram feitas entrevistas com o Gerente Industrial e com o proprietário da empresa Cerâmica Alfa. As entrevistas foram realizadas no segundo semestre de 2010. À exceção do nome da empresa, todos os demais dados são reais.

De forma complementar à coleta de dados primários, foi realizado um levantamento de informações sobre o setor nacional de cerâmica vermelha para, de forma breve, caracterizar a atividade produtiva desenvolvida, além de coletar dados sobre a ecoinovação verificada a partir de documentos publicados pelo fornecedor da tecnologia em questão. $\mathrm{O}$ tratamento dos dados ocorreu de modo qualitativo, através da análise comparativa entre os conceitos contidos nos modelos teóricos destacados e a prática da empresa.

\section{ANÁLISE E DISCUSSÃO DOS RESULTADOS}

A produção da indústria de cerâmica vermelha é direcionada ao setor da construção civil, cuja demanda é afetada diretamente pelas políticas públicas nacionais. Da mesma forma, a regulamentação estabelecida pela legislação vigente afeta diretamente as condições sob as quais as empresas desses setores devem operar, implicando exigências de diversas naturezas, dentre as quais, a regulamentação visando à redução do impacto ambiental que esses setores podem causar através de suas atividades produtivas.

Notadamente, os impactos ambientais decorrentes da produção do setor de cerâmica vermelha estão geralmente associados a fatores como: consumo e tipo de combustível utilizado; consumo de água no processo produtivo; emissão de poluentes gasosos, líquidos e sólidos; ocupação e degradação do solo; transportes de materiais de consumo e produtos cerâmicos; esgotamento de jazidas; perdas no processo produtivo e consequente geração de resíduos sólidos (Grigoletti \& Sattler, 2003). Esses fatores podem ser verificados nas diferentes etapas do sistema produtivo das empresas do setor de cerâmica vermelha.

De acordo com o Serviço Brasileiro de Apoio às Micro e Pequenas Empresas (SEBRAE, 2010), pode-se dividir o sistema produtivo das empresas de cerâmica vermelha nos seguintes grupos: processo de matéria-prima, processo de beneficiamento, processo de fabricação e processo de queima e inspeção. No processo de matéria-prima realiza-se coleta, sazonamento, estoque e mistura; no processo de beneficiamento realizam-se as atividades de misturador e laminador; e no processo de fabricação, a extrusão, as atividades de corte e prensa.

Revista de Administração e Inovação, São Paulo, v. 9, n.3, p. 154-174, jul/set. 2012. 
Cada empresa do setor gerencia as atividades de seu sistema produtivo em função de critérios particulares, levando em conta a capacidade produtiva, o tipo de tecnologia utilizada, a quantidade de mão de obra utilizada, a capacidade de armazenagem, a demanda de mercado atendida etc., de forma que mesmo as etapas do processo produtivo sendo comuns à produção de telhas, tijolos e blocos de argila, é importante conhecer o processo produtivo de cada empresa para entender suas potencialidades e restrições, técnicas e econômicas, e os efeitos nas dimensões sociais e ambientais relativas à atividade produtiva.

\subsection{A Cerâmica Alfa}

A empresa Cerâmica Alfa foi fundada na zona rural do município de Santa Luzia-PB em agosto de 1997. A referida empresa iniciou suas atividades produzindo telhas, tijolos e blocos cerâmicos em pequena escala (em torno de 300 mil peças/mês), para suprir a demanda de uma empresa específica, a Madeireira Alfa (nome fictício) também pertencente ao proprietário da Cerâmica Alfa. Com os bons resultados obtidos com o trabalho da Cerâmica Alfa, sua capacidade produtiva foi aumentada, como também houve expansão de sua cobertura de mercado, que além da demanda local dos clientes da Madeireira Alfa, incluiu o atendimento aos mercados de cidades circunvizinhas.

Atualmente a Cerâmica Alfa é classificada como pequena empresa, segundo critérios do SEBRAE (2010), e tem uma receita anual estimada de R\$ 1. 872.000,00, produzindo em torno de 7.275 milheiros de telhas/ano, 6.789 tijolos/ano e 174 milheiros de blocos/ano. A empresa é dirigida pelo seu proprietário e mantém 61 funcionários, dos quais 58 trabalham na produção e os demais, em atividades administrativas, sendo um gerente geral de produção, um auxiliar de escritório e um controlador de expedição. O período de maior demanda pelos produtos da empresa ocorre entre os meses de janeiro e março. Os maiores custos de produção se referem à aquisição de lenha, energia elétrica e argila.

\subsubsection{Sistema produtivo da Cerâmica Alfa}

Na Cerâmica Alfa, o sistema produtivo é dividido nas seguintes etapas:

a) Extração de matéria-prima: A principal matéria-prima da produção de cerâmica vermelha é a argila. Toda argila que abastece o processo produtivo da Cerâmica Alfa é adquirida por meio de extração nos rios e barreiros existentes na região próxima à empresa, não sendo utilizadas jazidas. A extração é feita a céu aberto através de um trator com uma pá carregadeira, e o transporte do local de 
extração até a fábrica é realizado por caminhões caçambas, que percorrem uma distância de aproximadamente $60 \mathrm{~km}$. Geralmente a argila é separada em montes, em função das diferentes camadas de solo de onde foi retirada e do tipo de argila identificado (forte ou fraca). A extração da argila é feita nos períodos de seca, entre os meses de novembro a maio.

b) Estocagem de matéria-prima: $\mathrm{O}$ estoque de argila é feito por um longo período de tempo, ficando esse material a céu aberto a fim de que obtenha características adequadas para seu processamento posterior. Esta forma de estocagem é chamada de sazonamento. No pátio da empresa a argila coletada é separada em montes de acordo com suas características. Assim, a argila mais fraca aquela com maior quantidade de areia (argila clara) - e a mais forte - aquela com menor quantidade de areia (argila escura) - ficam estocadas em locais específicos para não se misturarem. A empresa mantém um estoque alto de argila, o que favorece a continuidade do processo produtivo. Do pátio de estocagem, as argilas são transferidas através de um trator para o local de homogeneização ou mistura.

c) Mistura: A etapa de mistura corresponde à preparação da argila antes que a mesma seja encaminhada ao caixão alimentador. Nesta etapa são misturados os dois tipos de argila, a fraca e a forte, na proporção 2:1. A finalidade é corrigir a plasticidade da argila mantendo a mistura homogênea, para tanto se adiciona água para umedecer e facilitar a homogeneização da argila. Nesta etapa, além de um trator com pá carregadeira, utiliza-se a colaboração de um ou mais operários para retirar pedras e raízes, e quebrar possíveis torrões, a fim de facilitar a homogeneização da argila. A mistura obtida fica então à disposição da etapa de alimentação.

d) Alimentação: Consiste no transporte da mistura do pátio até um caixão alimentador. Essa movimentação é feita com um trator com a pá carregadeira que irá viabilizar a alimentação constante da argila na esteira de entrada ao processo de fabricação. O caixão alimentador é uma estrutura de elevada resistência que permite o acondicionamento de um volume significativo de argila.

e) Laminação: O laminador fica logo abaixo do caixão alimentador e é ligado a um equipamento que retira pedras ainda existentes na massa. O laminador fraciona as pequenas pedras, laminando-as e misturando-as à massa cerâmica. É importante destacar que a qualidade da laminação determina a qualidade do acabamento dos produtos e pode levar a uma redução no consumo de energia para queima, visto que a granulometria do material diminui. Esta etapa evita perdas na produção e proporciona produtos com melhor acabamento.

f) Extrusão: A etapa de extrusão é a responsável pela modelagem da argila. A extrusão consiste em forçar, por pressão, a massa a passar através de um bocal apropriado ao tipo de peça a ser produzida. As estrusoras utilizadas são recomendadas para a fabricação de tijolos aparentes, bem como telhas que necessitam de uma massa mais homogênea e uniforme. As extrusoras de tijolos, blocos e telhas possuem dois caracóis, sendo o primeiro para o recebimento da argila e o segundo na extrusão.

Revista de Administração e Inovação, São Paulo, v. 9, n.3, p. 154-174, jul/set. 2012. 
g) Corte: Na saída do fluxo da extrusora está a mesa de corte, formada por arames presos a um esquadro de metal. Esta etapa utiliza um sistema de corte horizontal que, por ser mais preciso, reduz as rebarbas e deformações nos elementos de argila. Depois do corte, os produtos são transportados através de carrinhos de mão apropriados até a área de secagem do produto semiacabado.

h) Secagem: A secagem do tijolo é feita em um galpão coberto onde é armazenado como produto semiacabado. No verão os tijolos alcançam a secagem em oito dias. No inverno esse processo dura até quinze dias. A secagem da telha ocorre no pátio da empresa, utilizando-se a exposição desse produto durante um dia. Vale salientar que, no caso de ocorrer chuva, toda a produção é perdida. No inverno, a produção de telha é prejudicada, já que a empresa não tem uma forma alternativa de secagem das telhas.

i) Queima: De todas as etapas, a queima é a mais importante, pois é nesta etapa que o produto cerâmico sofre alterações e transformações químicas e físicas dentro do forno. A queima das telhas é feita em fornos Caipiras, aquecidos a lenha de forma lenta e gradual até atingir o ponto final da queima. Quanto aos tijolos e blocos, estes são queimados em um forno Hoffman que possui controle da temperatura, mas também é aquecido a lenha.

j) Estocagem do produto acabado e Expedição: As telhas, os blocos e os tijolos prontos são armazenados a céu aberto em uma plataforma nas laterais do forno, sem identificação de quantidade e qualidade. Na expedição, enquanto o caminhão é carregado, o motorista dirige-se ao escritório para solicitar a nota fiscal dos produtos a serem transportados. Após o carregamento o carro passa pela conferência do responsável pelo setor de expedição e é liberado para seguir viagem até o destino especificado pelo comprador da carga dos produtos.

Cada etapa do processo produtivo pode gerar um tipo específico de impactos ambientais, de maior ou menor proporção. De forma geral, os principais impactos ambientais decorrentes das atividades produtivas da empresa Cerâmica Alfa são: degradação do solo na extração de argila; a poluição do ar através da emissão de $\mathrm{CO}_{2}$, poeira e cinza; e os desperdícios no consumo de recursos naturais como energia, água e argila, em função das perdas de produtos semiacabados ou acabados. Além desses, a exposição ao sol, ao calor do forno, à poeira e ao ruído são fatores que afetam a saúde do trabalhador em função das condições de trabalho verificadas. Do ponto de vista econômico, os custos de produção são aumentados devido ao desperdício de matéria-prima e da tentativa de reaproveitamento dos materiais perdidos.

$\mathrm{Na}$ etapa de corte, por exemplo, foi identificada a geração de resíduos sólidos na forma de aparas do corte, além de telhas, tijolos e blocos defeituosos e arame desgastado no processo. É 
importante destacar que os tijolos e telhas defeituosos no corte geram desperdícios dos recursos utilizados na sua produção, principalmente relacionados ao consumo de água, energia elétrica e argila, o que ocorre também com os desperdícios com aparas do corte. Além das perdas durante o corte, também podem acontecer perdas nas etapas de queima e expedição. O proprietário estima que a empresa registre $10 \%$ de perdas de produtos.

\subsubsection{O processo de queima e o tipo de inovação adotada}

A queima tem grande importância porque é nessa etapa que o produto cerâmico sofre alterações e transformações químicas e físicas dentro do forno. A forma como a empresa realiza a queima de seus produtos determina a capacidade de atendimento da demanda do mercado e as condições de atendimento dessa demanda, em termos de qualidade, tendo em vista que dessa etapa saem os percentuais de produção de primeira qualidade e os de produtos defeituosos; finalmente, em decorrência das perdas nessa etapa, é indicado o nível de consumo de recursos para que a empresa possa obter a quantidade de produtos planejados sem defeitos e, consequentemente, a intensidade do impacto ambiental resultante.

Especificamente analisando a intensidade do impacto ambiental resultante na etapa da queima, destacam-se: o alto consumo da lenha para o forno e a poluição do ar pela emissão de cinzas e $\mathrm{CO}_{2}$. Segundo informações do proprietário, a lenha utilizada nessa etapa é de plantio, e por isso não necessita de certificação ambiental. No que tange à saúde do trabalhador, os prejuízos dessa etapa estão relacionados à exposição ao calor do forno.

A produção média atual de telhas na Cerâmica Alfa é de 7.276 milheiros por ano, e a queima desses produtos é feita atualmente em fornos Caipiras, conforme ilustrado na Figura 1. As telhas, após a secagem, são levadas ao forno para a queima e organizadas para assegurar uma boa utilização do espaço. Esse forno é aquecido a lenha de forma lenta e gradual até atingir o ponto final da queima. Feito isso, deixa-se de alimentar o forno com a lenha e espera-se a temperatura decrescer até a temperatura ambiente. 


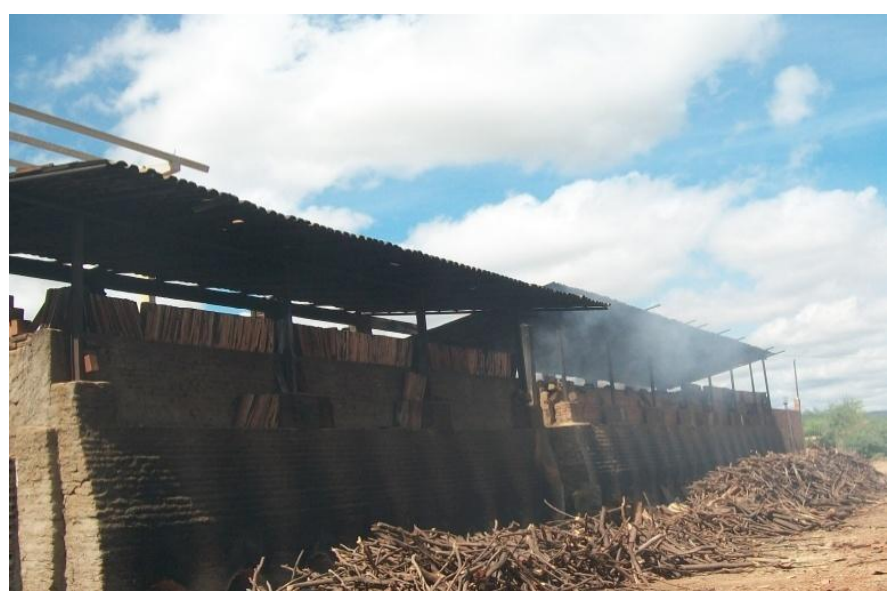

Figura 1 - Forno Caipira.

Fonte: Elaborado pelos autores.

A temperatura no forno Caipira é controlada apenas pela experiência do queimador de forno. Dessa forma ela pode assumir variações de temperatura que leve a queima do produto além do desejado e no nível de qualidade e uniformidade esperadas. Como resultado, consegue-se cerca de $30 \%$ de produção de primeira qualidade, para as quais existe grande procura no mercado e permite à empresa uma lucratividade maior. Além dessa parcela de primeira qualidade, a queima artesanal faz com que $43 \%$ de telhas sejam de segunda e $17 \%$, de terceira qualidade. Os $10 \%$ restantes são os produtos defeituosos ou quebrados. Esses dados da empresa demonstram que a utilização do forno Caipira não permite a monitoração da temperatura, o que acaba gerando muitos produtos defeituosos.

Para reduzir as perdas na fase da queima e os impactos ambientais inerentes a essa etapa do processo produtivo, a empresa Cerâmica Alfa investiu na compra de um forno Cedan para queima das telhas. A tecnologia contida no novo forno permite a melhoria da eficiência do processo produtivo como um todo e reduz os impactos ambientais decorrentes, principalmente os verificados na etapa da queima.

Esse forno foi idealizado e patenteado pelo proprietário da Cerâmica Dantas, localizada na cidade de Russas/Ceará. A iniciativa para o desenvolvimento do projeto foi para atender a necessidade de muitas cerâmicas de poder aumentarem sua produtividade por meio da instalação de um forno mais eficiente (Revista da Anicer, 2010).

O desenvolvimento do Forno Cedan teve como objetivo minimizar os principais problemas na produção da cerâmica vermelha, tais como: o controle da queima dos materiais industrializados; a qualidade das peças; reduzir o nível de calor que os operadores de forno recebem das fornalhas. Todas essas demandas das empresas do setor de cerâmica vermelha propiciaram a aceitação dessa inovação tecnológica. Atualmente, a Cerâmica Dantas já comercializou trinta e três fornos na Região Nordeste,

Revista de Administração e Inovação, São Paulo, v. 9, n.3, p. 154-174, jul/set. 2012. 
dos quais um está em fase final de construção na empresa Cerâmica Alfa (Revista da Anicer, 2010). A Figura 2 ilustra a instalação do novo forno na Cerâmica Alfa.

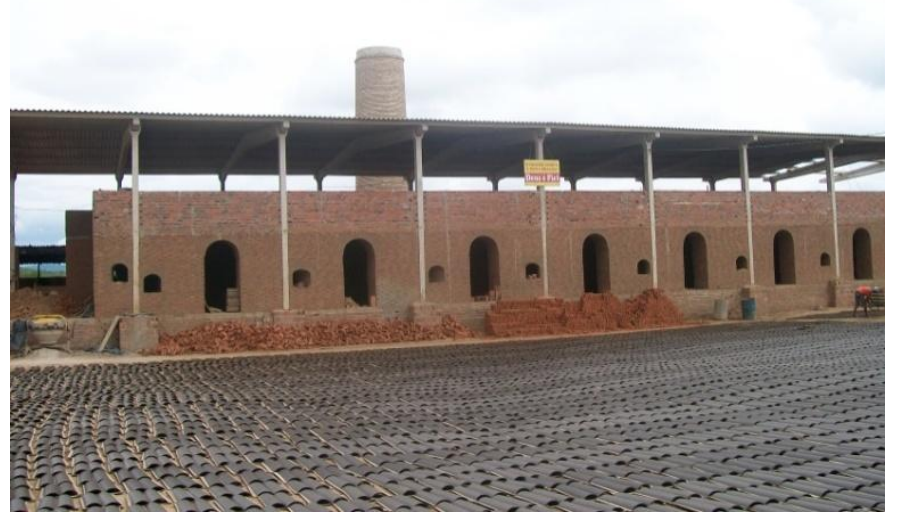

Figura 2 - Forno Cedan em construção na Cerâmica Alfa

Fonte: Elaborado pelos autores.

O Forno Cedan que está sendo construído na Cerâmica Alfa possui 12 câmeras que são rigorosamente monitoradas, proporcionando o reaproveitamento de até $80 \%$ do calor gerado na queima, com a possibilidade de transferência de calor das várias células em até 90\% para estufas, que serão construídas para esse fim. Dentre os benefícios da utilização do Forno Cedan, são indicados pelo fabricante:

\begin{tabular}{|c|}
\hline Benefícios da Utilização do Forno Cedan \\
\hline Redução de lançamentos de poluentes; \\
\hline Redução do uso de combustível em até 75\%; \\
\hline Praticidade e custo reduzido na construção; \\
\hline Construção com blocos manufaturados na empresa adquirente do forno; \\
\hline Baixo custo de manutenção; \\
\hline Retorno do investimento em 20 meses; \\
\hline Simplicidade operacional (facilidade de monitoramento); \\
\hline Reciclagem em até 80\% do calor gerado pela queima; \\
\hline Possibilidade de transferência de calor das várias células em até 90\% para estufas; \\
\hline Homogeneidade em cores e dimensões das peças, resultando a quase totalidade em peças de primeira qualidade; \\
\hline Queima mais amigável; \\
\hline Redução do extrativismo vegetal; \\
\hline
\end{tabular}

Quadro 1 - Benefícios da Utilização do Forno Cedan

Fonte: Forno Cedan (n.d.)

Revista de Administração e Inovação, São Paulo, v. 9, n.3, p. 154-174, jul/set. 2012. 
Como se pode observar, a nova tecnologia adquirida pela Cerâmica Alfa se incorpora ao seu sistema produtivo consistindo em uma ecoinovação integrada ao processo produtivo que implica a otimização de uma de suas mais importantes etapas: a queima. Essa avaliação foi feita com base no Modelo Hohmeyer e Koeschel (citado em Rennings, 2000).

\subsection{Fatores Determinantes na Adoção de Ecoinovação para a Empresa}

O proprietário da Cerâmica Alfa teve conhecimento do desenvolvimento do Forno Cedan em uma feira do setor realizada no segundo semestre de 2009. Um dos motivos que despertou interesse na aquisição do Forno Cedan foi a possibilidade de reduzir desperdícios na produção e a elevação da qualidade dos produtos em função do controle da temperatura no forno. Com a elevação da eficiência dos recursos produtivos, além da qualidade dos produtos, os custos de produção também podem ser reduzidos. Esses dois benefícios possibilitariam à empresa a ampliação de parcela de mercado e o melhor desempenho de seu sistema produtivo, principalmente nas épocas de chuva.

Outro fator que também motivou a aquisição do Forno Cedan pela Cerâmica Alfa foi a possibilidade de construção de uma estufa que será aquecida através do reaproveitamento do calor gerado pelo forno. Essa estufa permitirá secar as telhas artificialmente evitando o desperdício de peças devido à exposição ao ar livre, com risco de chuva nos períodos de inverno.

$\mathrm{Na}$ opinião do proprietário, a adoção dessa tecnologia de queima pode diferenciar a empresa mediante seus concorrentes pelo fato de reduzir os custos de produção e influenciar na qualidade dos produtos. Por outro lado, o valor investido na aquisição do Forno Cedan, incluindo projeto e construção, foi de $\mathrm{R} \$ 25.000,00$, e terá retorno aproximadamente em 20 meses.

A produção atual de telhas da empresa ainda com base na produção com forno Caipira gira em torno de 7.276 milheiros por ano. Com a utilização do novo forno pretende-se aumentar $30 \%$ o volume de produção. Mais especificamente, com a utilização do Forno Cedan espera-se um aumento de $15 \%$ na quantidade de telhas de primeira qualidade e uma redução de 5\% nas peças defeituosas ou quebradas e de terceira qualidade. Numa análise comparativa são necessárias apenas 18 horas para produzir de 13 a 20 mil telhas. Nos fornos convencionais, como o Caipira, esse processo pode levar de 30 a 70 horas.

A utilização do Forno Cedan reduz o volume relativo de consumo de lenha. Na empresa hoje, o consumo médio de lenha para cada mil telhas produzidas gira em torno de dois quilos. A projeção de consumo de lenha para a mesma quantidade de produto com o Forno Cedan é de que serão necessários

Revista de Administração e Inovação, São Paulo, v. 9, n.3, p. 154-174, jul/set. 2012. 
apenas 700g de lenha. Diante dessas projeções, os ganhos econômicos ficam evidentes. Por outro lado, os ganhos ambientais também se manifestam com a redução do consumo de lenha, pois ocorre a redução de desperdícios do recurso natural extraído e utilizado no processo (argila e água, respectivamente), bem como se reduz a liberação de gases do tipo $\mathrm{CO}_{2}$ na etapa da queima.

A incorporação dessa nova tecnologia ao sistema produtivo da Cerâmica Alfa caracteriza-se como uma ecoinovação predominantemente empurrada pelo desenvolvimento tecnológico, tendo em vista seus objetivos de maior eficiência no uso de energia (queima da lenha), no uso dos materiais (elevação da produtividade da argila e da água consumidas na produção), na qualidade do produto (controle de qualidade das peças produzidas). Essa ecoinovação foi desenvolvida por uma empresa do setor (a Cerâmica Dantas) que se tornou fornecedora de tecnologia para as empresas do setor, sendo incorporada ao processo de produção em função da necessidade da Cerâmica Alfa em ampliar sua capacidade produtiva.

É importante também considerar que os fatores relacionados às preferências e às demandas de consumidor também foram considerados pela Cerâmica Alfa na decisão por adquirir a nova tecnologia, o que pode revelar que a empresa estudada está despertando a visão sobre a importância da gestão ambiental não só como meio de reduzir os impactos decorrentes de sua atividade produtiva, como também como recurso estratégico para competição no mercado.

\section{CONCLUSÕES}

Os principais impactos ambientais decorrentes das atividades produtivas do setor de cerâmica vermelha são: degradação do solo na extração de argila, a poluição do ar através da emissão de $\mathrm{CO}_{2}$, poeira e cinza; e os desperdícios no consumo de recursos naturais como energia, água e argila em função das perdas de produtos semiacabados ou acabados. Do ponto de vista econômico, os custos de produção são aumentados devido ao desperdício de matéria-prima e do esforço de reaproveitamento dos materiais perdidos. Por outro lado, a exposição ao sol, ao calor do forno e à poeira são fatores que afetam a saúde do trabalhador.

Diante desse contexto, a adoção de uma ecoinovação incorporada a uma ou mais etapas do processo produtivo pode elevar a eficiência do sistema produtivo como um todo, melhorar as condições de trabalho e ao mesmo tempo reduzir o impacto ambiental, além de se tornar cada vez mais necessária para a sustentabilidade das atividades produtivas das empresas do setor de cerâmica vermelha. 
No caso estudado, a nova tecnologia adquirida, que irá substituir a forma como uma das etapas do processo produtivo da Cerâmica Alfa, pode proporcionar ganhos econômicos, sociais e ambientais, por se constituir uma ecoinovação integrada ao processo produtivo que implicará a otimização de uma de suas mais importantes etapas: a queima.

A aquisição e utilização do novo forno para a queima dos produtos da empresa caracterizam-se como uma ecoinovação predominantemente empurrada pelo desenvolvimento tecnológico, tendo em vista seus objetivos de maior eficiência no uso de energia (queima da lenha), no uso dos materiais (elevação da produtividade da argila e da água consumidas na produção), na qualidade do produto (controle de qualidade das peças produzidas).

É importante também considerar que, ainda que a referida ecoinovação adotada tenha sido incorporada ao processo de produção em função da necessidade de a Cerâmica Alfa ampliar sua capacidade produtiva e elevar a eficiência de seus recursos produtivos, fatores relacionados às preferências e às demandas do mercado consumidor também foram considerados, o que pode indicar que a empresa estudada está despertando a visão sobre a importância da gestão ambiental não só com o imprescindível propósito de reduzir os impactos decorrentes de sua atividade produtiva, mas também como recurso estratégico para competição no mercado.

Destacam-se os importantes ganhos ambientais com a substituição do forno Caipira pelo Forno Cedan: redução do extrativismo de madeira e combustível para a queima de produtos, além da redução de poluentes com a queima; redução dos resíduos derivados das perdas de produtos defeituosos; e redução no consumo de água e de argila do processo produtivo em função da elevação da produtividade desses recursos.

Da mesma forma, ganhos sociais relativos à melhoria das condições de trabalho em uma das mais importantes e insalubres etapas da produção de telhas, tijolos e blocos de cerâmica vermelha também poderão ser verificados, tais como: menores níveis de temperatura em um local que é naturalmente quente (fornalha); menor exposição ao sol; menor exposição à fumaça; e simplicidade operacional, permitindo a manutenção da mão de obra local sem redução do emprego.

Assim, embora a ecoinovação adotada tenha sido predominantemente impulsionada pelos ganhos econômicos para a empresa, tendo em vista a sua necessidade de expansão para atingir maior parcela da demanda e a melhoria da eficiência dos recursos produtivos, há ganhos ambientais e sociais envolvidos que contribuem para a sustentabilidade da atividade econômica. 


\section{REFERÊNCIAS}

Associação Brasileira de Cerâmica. (2003). Números do setor de cerâmica vermelha no Brasil. Recuperado em 20 de julho, 2010, de http://www.abceram.org.br/asp/abc_283.asp.

Barbieri, J. C., \& Simantob, M. A. (Orgs.). (2007). Organizações inovadoras sustentáveis: uma reflexão sobre o futuro das organizações. São Paulo: Atlas.

Barbieri, J. C., Vasconcelos, I. F. G., Andreassi, T., \& Vasconcelos, F. C. (2010). Inovação e sustentabilidade: novos modelos e proposições. Revista de Administração de Empresas, 50(2), 146154.

Berkhout, F., \& Green, K. (2002). Managing innovation for sustainability: the challenge of integration and scale. International Journal of Innovation Management, 6(3), 227-232.

Cohen, C. (2003). Padrões de consumo e energia: efeitos sobre o meio ambiente e o desenvolvimento. In P. H. May, M. C. Lustosa, \& V. Vinha (Orgs.), Economia do meio ambiente: teoria e prática (pp. 245-269). Rio de Janeiro: Elsevier.

Forno Cedan. (n.d.). Vantagens do Forno Cedan. Recuperado em 10 de janeiro, 2011, de http://www.fornocedan.com.br/.

Gasi, T. M. T., \& Ferreira, E. (2006). Produção mais limpa. In A. Vilela Jr., \& J. Demajorovic (Orgs.), Modelos e ferramentas de gestão ambiental: desafios e perspectivas para as organizações (pp. 4184). São Paulo: SENAC.

Gil, A. C. (1996). Como elaborar projetos de pesquisa (3a ed.). São Paulo: Atlas.

Grigoletti, G. C., \& Sattler, M. A. (2003). Estratégias ambientais para indústrias de cerâmica vermelha no Estado do Rio Grande do Sul. Ambiente Construído, 3(3), 19-32.

Hair, J. F., Jr., Babin, B., Money, A. H., \& Samouel, P. (2005). Fundamentos de métodos de pesquisa em administração. Porto Alegre: Bookman.

Hall, J. (2000). Environmental supply chain dynamics. Journal of Cleaner Production, 8(6), 455-471.

Leite, P. R. (2009). Logística reversa: meio ambiente e competitividade (2a ed.). São Paulo: Prentice Hall.

Rennings, K. (2000). Redefining Innovation - eco-innovation research and the contribution from ecological economics. Ecological Economics, 32(2), 319-332.

Revista da Anicer. (2010). Nova opção em forno intermitente. Recuperado em 10 de janeiro, 2010 de http://www.anicer.com.br/index.asp?pg=institucional_direita.asp\&secao=10\&ex=6\&edicao=65.

Romeiro, A. R. (1999). Desenvolvimento sustentável e mudança institucional: notas preliminares (Texto para Discussão, n. 68). Campinas: Unicamp.

Sanchez, L. E. (2008). Avaliação de impacto ambiental: conceitos e métodos. São Paulo: Oficina de Textos. 
Schumpeter, J. A. (1985). Teoria do desenvolvimento econômico: uma investigação sobre lucros, capital, crédito, juro e ciclo econômico (Coleção dos Economistas). São Paulo: Abril Cultural.

Serviço Brasileiro de Apoio às Micro e Pequenas Empresas. Cerâmica vermelha para construção: telhas, tijolos e tubos (Série Mercado). 2008. Recuperado em 28 de abril, 2010, de http://201.2.114.147/bds/BDS.nsf/947CE75D32DE1BCB832574C1004E1EC5/\$File/NT00038DA6 .pdf.

Teles, V. K., \& Arraes, R. A. (2004). Environmental protection and economic growth. Anais do Encontro Nacional de Economia, João Pessoa, PB, 32.

Vinha, V. (2003). As empresas e o desenvolvimento sustentável: da eco-eficiência à responsabilidade social corporativa. In P. H. May, M. C. Lustosa, \& V. Vinha (Orgs.), Economia do meio ambiente: teoria e prática (pp. 173-196). Rio de Janeiro: Elsevier.

\title{
ECO-INNOVATION USE OF MANUFACTURING IN THE PROCESS OF RED CERAMIC
}

\begin{abstract}
This study aimed to present and characterize an example of eco-innovation adopted by a company of the red ceramic sector. A case study was performed and classified the types of eco-innovation in the production process of the company. The data analysis occurred by using mainly the models of Hohmeyer e Koeschel (as cited in Rennings, 2000) and Rennings (2000). The results pointed to the confirmation that the acquisition of a new furnace for the burning step is part of the eco-innovation process which has in the technological development of the market supply its main determinant factor.
\end{abstract}

Key words: Eco-innovation; Determinant factors in the adoption of Eco-innovation; Red Ceramic Manufacturing; Environmental Management.

Data do recebimento do artigo: 17/03/2012

Data do aceite de publicação: 10/07/2012

Revista de Administração e Inovação, São Paulo, v. 9, n.3, p. 154-174, jul/set. 2012. 